\title{
On $\mathrm{Ca}^{2+}$ signalling research
}

\author{
LENG FangWei \\ Institute of Biophysics, Chinese Academy of Sciences, Beijing 100101, China
}

Received May 15, 2012; accepted July 8, 2012

Citation: Leng F W. On Ca ${ }^{2+}$ signalling research. Sci China Life Sci, 2012, 55: 744-746, doi: 10.1007/s11427-012-4358-Z

As a highly versatile intracellular signal, calcium $\left(\mathrm{Ca}^{2+}\right)$ regulates many different cellular processes in both animal and plant systems. Disruption of $\mathrm{Ca}^{2+}$ homeostasis contributes to several human diseases. Owing to the importance of $\mathrm{Ca}^{2+}$ signalling, its research is now an active field in life science. There are numerous $\mathrm{Ca}^{2+}$ signalling systems, consisting of a diverse array of signalling units that deliver $\mathrm{Ca}^{2+}$ signals with different spatial and temporal properties $[1,2]$, playing roles in ubiquitous biological processes including gene regulation, fuel generation, substance transport, hormone and neurotransmitter secretion, cell motility and muscle contraction [3]. Consequently, exquisite homeostasis of $\mathrm{Ca}^{2+}$ cycling is the key for health of humans, the disruption of which is related to many human diseases such as heart failure, neuron-degeneration, and diabetes [4-6].

Many remarkable achievements have greatly enhanced our understanding of $\mathrm{Ca}^{2+}$ signaling, including those from Chinese scientists [7-10]. The 17th International Symposium on $\mathrm{Ca}^{2+}$-binding Proteins and $\mathrm{Ca}^{2+}$ Function in Health and Disease was held in Beijing, China, on July 16-20, 2011 [11], accompany which, a special issue of Science China Life Sciences was published for transducing $\mathrm{Ca}^{2+}$ signals to effectors.

The first part focused on the mechanisms in maintaining a low cytosolic level of $\mathrm{Ca}^{2+}$, with two articles reviewing the properties of the plasma membrane calcium ATPases (PMCA) in ejecting $\mathrm{Ca}^{2+}$ into the extracellular space. First, Carafoli [12] reviewed the role of the plasma membrane calcium pump, PMCA2, in the hearing process. As an im-

email: fangweihaha7@gmail.com portant plasma membrane $\mathrm{Ca}^{2+}$ ATPases, PMCA2 plays an important role in maintaining intracellular $\mathrm{Ca}^{2+}$ homeostasis in the inner ear. It is involved in the maintenance of intracellular free calcium levels and the dysfunction of which leads to deafness. Recent studies show that another important isoform of PMCA, PMCA4, has a number of roles for heart functioning [13,14]. Cartwright et al. [15] then reviewed the roles of plasma membrane calcium pumps related to cardiovascular disease, focusing on PMCA4, including its function in heart and vasculature, linking PMCA4 to contractile function, cardiac hypertrophy, cardiac rhythm, blood pressure control and hypertension. Undoubtedly, further understanding of the roles of PMCAs will facilitate the development of new treatment strategies for related diseases.

As a versatile intracellular messenger, $\mathrm{Ca}^{2+}$ performs roles in many different ways to regulate cellular processes [16]. The second part of this special issue focuses on mechanisms for spatiotemporally-specific increases in cytosolic $\mathrm{Ca}^{2+}$. First, Lee [17] reviewed studies on the fraternal twin messengers for calcium signaling, cyclic ADP-ribose (cADPR) and nicotinic acid adenine dinucleotide phosphate (NAADP). Since the initial finding by Lee and his colleagues that cADPR and NAADP could liberate stored $\mathrm{Ca}^{2+}$, they have been shown to be active in mobilizing $\mathrm{Ca}^{2+}$ in a wide range of cells spanning three biological kingdoms. He summarized the cADPR/NAADP/CD38signalling pathway and also described the structure and function of its components. Kimlicka and van Petegem [18] then reviewed the structural biology aspect of ryanodine receptors (RyRs) which are high-conductance ion channels 
located in the endoplasmic/sarcoplasmic reticulum (ER/SR). They summarized studies using electron microscopy, NMR, and X-ray crystallography. Being permeable to $\mathrm{Ca}^{2+}$, RyRs plays important roles in various physiological processes [19], especially in the contraction of cardiac and skeletal muscle. RyRs are the largest known ion channels, presenting great challenges for the structural biology research.

The identification of target proteins is very important for understanding the physiological roles of $\mathrm{Ca}^{2+}$ mobilizing messengers. Recent studies indicate that NAADP acts upon a novel family of endo-lysosomal channels in animal cells termed two-pore channels (TPCs) [20,21]. Galione et al. [22] then summarized the physiological roles of NAADPmediated $\mathrm{Ca}^{2+}$ signalling. They provided a historical perspective on the research of TPCs, studies on which unveiled the physiological role of NAADP as an intracellular $\mathrm{Ca}^{2+}$ mobilizing messenger. The roles of calcium and actin for fertilization, as mediated by a novel NAADP-gated channel in the plasma membrane of starfish oocytes, were then reviewed by Santella and Chun [23].

Alzheimer's disease (AD), an irreversible and progressive neurodegenerative disorder, currently affects approximately 27 million people worldwide. There is still no effective way to treat such diseases and our understanding of it is still limited. Maintenance of intracellular $\mathrm{Ca}^{2+}$ homeostasis is essential for the functioning and survival of neurons and is a fundamental component of synaptic transmission for both pre- and postsynaptic mechanisms $[1,24]$. Recent studies suggest that disrupted neuronal $\mathrm{Ca}^{2+}$ signalling may contribute to $\mathrm{AD}$ pathogenesis. The $\mathrm{Ca}^{2+}$ theory of $\mathrm{AD}$ is now becoming increasingly popular. The next two reviews focused on the $\mathrm{Ca}^{2+}$ theory of AD. First, Supnet and Bezprozvanny [25] discussed Alzheimer's disease pathogenesis related to presenilins as endoplasmic reticulum calcium leak channels. Chakroborty and Stutzmann [26] then discussed the early calcium dysregulation in Alzheimer's disease, overviewing the roles of $\mathrm{AD}$-linked $\mathrm{Ca}^{2+}$ signalling alterations in neurons and how this may be linked to synaptic dysfunctions at both early and late stages of the disease. The last review of this part focused on the distinctive characteristics and functions of multiple mitochondrial $\mathrm{Ca}^{2+}$ influx mechanisms [27]. As is well known, mitochondria is not just a $\mathrm{Ca}^{2+}$ buffering system, but also an important $\mathrm{Ca}^{2+}$ storage site [28,29]. This review summarized the current progress of mitochondrial $\mathrm{Ca}^{2+}$ influx pathways and their differences in kinetics, $\mathrm{Ca}^{2+}$ dependence, and pharmacological characteristics, and their potential physiological and pathological implications.

Another active field in $\mathrm{Ca}^{2+}$ signaling focuses on the function of various $\mathrm{Ca}^{2+}$-related proteins such as Caldesmon [30,31], Osteopontin [32], Cornulin [33], ERp44 [34] and others. The third part of this issue consists of three reviews, all focusing on the proteins that play important roles in cascades transducing $\mathrm{Ca}^{2+}$ signals to effectors. First, Maki et al. [35] summarized the structure and function of ALG-2, which is a penta-EF-hand $\mathrm{Ca}^{2+}$-binding protein, interacting with various proteins in a $\mathrm{Ca}^{2+}$-dependent fashion. Zhang and Trebak [36] then summarized the recent studies on the endoplasmic reticulum $\mathrm{Ca}^{2+}$ sensor STIM1 and the plasma membrane $\mathrm{Ca}^{2+}$ channel Orai1, pointing out that the contribution of STIM1 and Orai1 to cardiovascular diseases, and discussing the prospects for targeting them in the therapy of vascular diseases. Last but not least, Rivas et al. [37] summarized the recent advances in the construction of an interactome of DREAM, a calcium binding protein of the neuronal calcium sensor superfamily that plays an important role in cell physiology through the interaction with specific proteins. DREAM also can interact with downstream regulatory element (DRE) sites in the DNA to regulate transcription.

Although enormous progress and insights have been made on $\mathrm{Ca}^{2+}$ signalling, there is still many important questions remaining to be answered in the future. It is thus hoped that more studies on $\mathrm{Ca}^{2+}$ signalling will be carried out to provide better understanding of the cellular and molecular mechanisms of $\mathrm{Ca}^{2+}$ signalling, contributing to the development of therapeutics for various human diseases related to disruption of $\mathrm{Ca}^{2+}$ homeostasis. We hope that this special issue of Science China Life Sciences will be helpful for this, and stimulate researchers' interest in $\mathrm{Ca}^{2+}$ signaling studies.

1 Berridge M J, Lipp P, Bootman M D. The versatility and universality of calcium signalling. Nature Rev Mol Cell Biol, 2000, 1: 11-21

2 Carafoli E, Santella L, Brance D, et al. Generation, control, and processing of cellular calcium signals. Crit Rev Biochem Mol Biol, 2001, 36: 107-260

3 Berridge M J, Bootman M D, Roderick H L. Calcium signalling: dynamics, homeostasis and remodelling. Nat Rev Mol Cell Biol, 2003, 4: 517-529

4 Michels G, Khan I F, Endres-Becker J, et al. Regulation of the human cardiac mitochondrial $\mathrm{Ca}^{2+}$ uptake by 2 different voltage-gated $\mathrm{Ca}^{2+}$ channels. Circulation, 2009, 119: 2435-2443

5 Surmeier D J, Guzman J N, Sanchez-Padilla J. Calcium, cellular aging, and selective neuronal vulnerability in parkinson's disease. Cell Calcium, 2010, 47: 175-182

6 Verkhratsky A, Fernyhough P. Mitochondrial malfunction and $\mathrm{Ca}^{2+}$ dyshomeostasis drive neuronal pathology in diabetes. Cell Calcium, 2008, 44: 112-122

7 Zhao A J, Zheng M G, Wang G C. Silencing ABCE1 increases E-Cadherin expression and decreases cell invasion in 95-D/NCIH446 lung carcinoma cells. Prog Biochem Biophys, 2010, 37: 891-896

8 Su H F, Bao J L, Li P. Electromagnetic fields exposure elicits radical and $\mathrm{Ca}^{2+}$ response in rat-hippocampal neurons. Prog Biochem Biophys, 2010, 37: 313-318

9 Gong Y B, Jiang Q, Hu J Y, et al. The effects of protocadherin $18 \mathrm{~b}$ down regulation on embryonic neurogenesis in zebrafish. Prog Biochem Biophys, 2010, 37: 897-903

10 Liu P Q, Zhu K Q. The effects of activity of astrocytes on neuron dendritic filopodia motility. Prog Biochem Biophys, 2011, 38: 626-632

11 Wang S Q, Zhu M X, Carafoli E. $\mathrm{Ca}^{2+}$ : A versatile master key for intracellular signaling cascades. Sci China Life Sci, 2011, 54: 683-685

12 Carafoli E. The plasma membrane calcium pump in the hearing process: physiology and pathology. Sci China Life Sci, 2011, 54: 
686-690

13 Oceandy D, Cartwright E J, Emerson M, et al. Neuronal nitric oxide synthase signaling in the heart is regulated by the sarcolemmal calcium pump 4b. Circulation, 2007, 115: 483-492

14 Wu X, Chang B, Blair N S, et al. Plasma membrane $\mathrm{Ca}^{2+}$-ATPase isoform 4 antagonizes cardiac hypertrophy in association with calcineurin inhibition in rodents. J Clin Invest, 2009, 119: 976-985

15 Cartwright E J, Oceandy D, Austin C, et al. $\mathrm{Ca}^{2+}$ signalling in cardiovascular disease: The role of the plasma membrane calcium pumps. Sci China Life Sci, 2011, 54: 691-698

16 Berridge M J, Bootman M D, Roderick H L. Calcium signalling: dynamics, homeostasis and remodelling. Nat Rev Mol Cell Biol, 2003, 4: 517-529

17 Lee H C. Cyclic ADP-ribose and NAADP: Fraternal twin messengers for calcium signaling. Sci China Life Sci, 2011, 54: 699-711

18 Kimlicka L, van Petegem F. The structural biology of ryanodine receptors. Sci China Life Sci, 2011, 54: 712-724

19 Li Y M, Ji G J. Evolution in research of ryanodine receptors and its subtype 2 regulators. Prog Biochem Biophys, 2011, 38: 408-417

20 Calcraft P J, Ruas M, Pan Z, et al. NAADP mobilizes calcium from acidic organelles through two-pore channels. Nature, 2009, 459: 596-600

21 Brailoiu E, Churamani D, Cai X, et al. Essential requirement for two-pore channel 1 in NAADP-mediated calcium signaling. J Cell Biol, 2009, 186: 201-209

22 Galione A, Parrington J, Funnell T. Physiological roles of NAADP-mediated $\mathrm{Ca}^{2+}$ signaling. Sci China Life Sci, 2011, 54: 725-732

23 Santella L, Chun J T. Actin, more than just a housekeeping protein at the scene of fertilization. Sci China Life Sci, 2011, 54: 733-743

24 Berridge M J. Neuronal calcium signaling. Neuron, 1998, 21: 13-26

25 Supnet C, Bezprozvanny I. Presenilins as endoplasmic reticulum calcium leak channels and Alzheimer's disease pathogenesis. Sci China Life Sci, 2011, 54: 744-751
26 Chakroborty S, Stutzmann G E. Early calcium dysregulation in Alzheimer's disease: Setting the stage for synaptic dysfunction. Sci China Life Sci, 2011, 54: 752-762

27 Pan S, Ryu S Y, Sheu S S. Distinctive characteristics and functions of multiple mitochondrial $\mathrm{Ca}^{2+}$ influx mechanisms. Sci China Life Sci, 2011, 54: 763-769

28 Gunter T E, Pfeiffer D R. Mechanisms by which mitochondria transport calcium. Am J Physiol, 1990, 258: C755-786

29 Gunter T E, Buntinas L, Sparagna G, et al. Mitochondrial calcium transport: Mechanisms and functions. Cell Calcium, 2000, 28: 285-296

30 Jiang Q F, Cai S X, Yan X Q. The effect of caldesmon phosphorylation on metastatic tumor cell mobility. Prog Biochem Biophys, 2010, 37: 326-336

31 Cheng Y D, Han S Y, Zhao J F, et al. Calmodulin involved in the cell proliferation of root apical meristem and ABA response in Arabidopsis. Prog Biochem Biophys, 2011, 38: 36-45

32 Zhang X, Ye L H, Zhang X D. Osteopontin (OPN) upregulates calpain small subunit $1(\mathrm{Capn} 4)$ via nuclear factor- $\kappa \mathrm{B}$ in promotion of hepatoma cell migration. Prog Biochem Biophys, 2010, 37: 534539

33 Li G M, Chen Q, Dai K S, et al. The $\mathrm{Ca}^{2+}$-dependent multimerization of S100 domain in Homo sapiens cornulin protects cells from injury. Prog Biochem Biophys, 2011, 38: 239-247

34 Pan C Y, Zhou R B, Chen Z, et al. ERp44 mediates gene transcription via inositol 1,4,5-trisphosphate receptors in HeLa cells. Prog Biochem Biophys, 2011, 38: 706-712

35 Maki M, Suzuki H, Shibata H. Structure and function of ALG-2, a penta-EF hand calcium-dependent adaptor protein. Sci China Life Sci, 2011, 54: 770-779

36 Zhang W, Trebak M. STIM1 and Orai1: Novel targets for vascular diseases? Sci China Life Sci, 2011, 54: 780-785

37 Rivas M, Villar D, González P, et al. Building the DREAM interactome. Sci China Life Sci, 2011, 54: 786-792

Open Access This article is distributed under the terms of the Creative Commons Attribution License which permits any use, distribution, and reproduction in any medium, provided the original author(s) and source are credited. 